\title{
ANALISIS ISI KUANTITATIF BERITA KEGIATAN MAHASISWA
}

\author{
Ami Saptiyono \\ Program Studi Ilmu Komunikasi Universitas Semarang \\ ami.s@usm.ac.id \\ Erika Dwi Setya Watie \\ Program Studi Ilmu Komunikasi Universitas Semarang \\ errika@usm.ac.id \\ Edi Nurwahyu Julianto \\ Program Studi Ilmu Komunikasi Universitas Semarang \\ edi@usm.ac.id
}

Lembaga Penelitian dan Pengabdian kepada Masyarakat, Universitas Semarang, Indonesia

DOI: http://dx.doi.org/10.26623/jdsb.v21i2.1698

\begin{abstract}
Abstrak
Penelitian ini melihat bagaimana kegiatan mahasiswa, dalam hal ini mahasiswa Komunikasi Universitas Semarang yang dikonstruk dalam pemberitaan media massa online. Tribunnews.com dipilih karena merupakan portal berita terbesar dan terluas di Indonesia. Peneliti mencari dan melihat artikel kegiatan mahasiswa Ilmu Komunikasi Universitas Semarang yang dimuat oleh tribunews.com mulai periode Januari 2018 hingga Oktober 2019. Dengan menggunakan agenda setting, peneliti menganalisa kemampuan media massa membangun pesan dari sebuah berita dalam mempengaruhi khalayak. berdasarkan tujuan tertentu yang diinginkan oleh media atau pihak yang memiliki kepentingan. Analisis kuantitatif ini terdiri dari tiga tahap, yaitu; penentuan model desain penelitian, pencarian data primer, dan pencarian pengetahuan kontekstual sehingga hubungan antara faktor-faktor dalam penelitian dapat dilihat. Hasil penelitian ini menunjukan bahwa kualitas dan kuantitas kegiatan mahasiswa harus ditingkatkan agar mampu menmbuat media mengkonstruksi berita sesuai yang diinginkan oleh pihak yang memiliki kepentingan atas pemberitaan tersebut.

Kata Kunci: Jurnalisme Digital, Agenda Seting, Kegiatan Mahasiswa, Konstruksi Berita, Analisis isi Kuantitatif
\end{abstract}


Dinamika Sosial Budaya, Vol 22, No. 2, Desember 2020, pp 284-293

p-ISSN: 1410-9859\& e-ISSN: 2580-8524

http://journals.usm.ac.id/index.php/jdsb

\begin{abstract}
This study analyse how student activities, in this case is Semarang University Communication students activities, were constructed in online media news. Tribunnews.com was the media chose by authors, because it is the largest and widest news portal in Indonesia. Authors searched and looked at the Semarang University Communication Studies student activities articles which published by tribunews.com from January 2018 to October 2019. Using agenda setting, authors analyzed the ability of the mass media to build messages to make news according to the audience. Based on certain objectives desired by the media or parties who have an interest. This quantitative analysis consists of three hangovers, namely; The selection of research design models, primary data search, and contextual knowledge search so that the relationship between factors in research can be seen. The results of this study indicate that the quality and excellence of student activities must be improved in order to be able to make the media construct news as desired by those who have an interest in the reporting.
\end{abstract}

Keywords: Digital Journalism, Agenda Setting, Student Activities, News Construction Quantitative Content Analysis 


\section{PENDAHULUAN}

Kompetisi dalam menarik simpati
calon mahasiswa untuk melanjutkan pendidikan di universitas, dewasa ini semakin tinggi, bahkan kompetisi ini terjadi di antara fakultas dan departemen dalam sebuah universitas. Ini dapat dilihat dari berbagai cara yang mereka lakukan untuk menarik calon siswa baru mulai dari fasilitas, akreditasi, kualitas instruktur, kualitas kurikulum yang diajarkan dan banyak hal lain yang disorot untuk melakukannya. Salah satunya adalah jurusan Komunikasi Fakultas Teknologi Informasi dan Komunikasi, Universitas Semarang, yang berusaha untuk menarik calon mahasiswa tersebut dengan melakukan berbagai pengembangan dalam upayanya meningkatkan daya saing atas kompetitor dalam pasar Perguruan Tinggi (Tjiptono, 2015). Salah satu strategi yang digunakan adalah melalui kegiatan-kegiatan mahasiswa.

Kegiatan mahasiswa, yang bertujuan untuk menyalurkan dan mengembangkan minat bakat mahasiswa, serta bertujuan mempraktekan pengetahuan yang telah mereka dapatkan dalam kegiatan perkuliahan. (Anonymous, 2017). Kegiatan- kegiatan mahasiswa tersebut sekaligus berfungsi sebagai sarana promosi bagi Universitas Semarang, khususnya Program Studi Ilmu Komunikasi dalam menarik minat masyarakat untuk menjadi mahasiswa program studi ini. Hal ini dapat dicapai, apabila kegiatankegiatan mahasiswa tersebut mendapatkan dukungan dari media, salah satunya adalah berita yang dimuat dan dipublikasikan oleh media terutama media online yang memiliki kelebihan dalam kecepatan dan keluasan penyampaian pesan (Romli, 2015)

Publikasi media massa terutama dalam bentuk liputan berita, sangat membantu institusi dalam mencapai tujuan mereka. Akan tetapi, sering muncul perbedaan konstruksi pesan dalam pemberitaan yang dimuat oleh suatu media dengan sumber pesan. Perbedaan ini sering mengakibatkan kurang optimalnya tujuan yang ingin dicapai oleh institusi pembuat pesan. Salah satu media massa yang sering mempublikasikan kegitan-kegiatan mahasiswa adalah Tribunnews.com. sebagai media online terpopuler dengan jaringan terluas di Indonesia, Tribunnews.com mampu mempublikasikan berita dari berbagai pelosok Indonesia (Portnoy, 2018) termasuk diantaranya adalah kegiatan-kegiatan mahasiswa Program Studi Ilmu Komunikasi Fakultas Teknologi Informasi dan Komunikasi Universitas Semarang.

Meningkatnya penggunaan media online di bidang jurnalistik, juga dipengaruhi oleh karakteristik media online, Siapera dan Vegalis (2012) dan Bradshaw (2017) mengatakan bahwa pemilik media menggunakan media jenis ini dalam menyampaikan informasi kepada publik lebih disebabkan oleh kemampuannya. karakteristik unik (Bradshaw, 2017; Siapera \& Veglis, 2012) adalah; kebebasan audiens untuk menyusun berita yang akan dibacanya, kemampuan menyampaikan berita secepat mungkin dengan jangkauan yang sangat luas, memiliki kemampuan multimedia dalam menyajikan berita, berita di media ini bersifat mandiri, sehingga pembaca tidak perlu membaca keseluruhan berita, kemampuan untuk menyimpan berita tanpa batas dan dapat diakses oleh pembaca setiap saat, halaman berita tidak terbatas, karakteristik interaktif, yang memungkinkan pembaca dan penulis untuk berinteraksi. Pada artikel kali ini, penulis menggunakan teori cyber jurnalisme ini untuk melihat keunikan dan luasnya liputan berita Tribunnews.com menjangkau dan menarik pembacanya. 
Griffin (2019) McCombs, Shaw (2014) menyatakan bahwa agenda setting merupakan kemampuan media untuk mempengaruhi khalayak yang disebabkan oleh kemampuan media massa dalam mentransfer informasi penting dalam agenda beritanya ke agenda publik. Kemampuan inilah yang sering disebut dengan Agenda Setting, yang menjadikan media mampu mempengaruhi dan membentuk persepsi khalayak pembacanya. Di sisi lain, teori agenda setting ini juga mendukung pernyataan bahwa setiap individu memiliki kebebasan untuk memilih dan menentukan apa yang akan diterimanya (Grififn, 2019; McCombs et al., 2014)

McComb \& Shaw dalam Griffin (2019), juga menyatakan bahwa teori agenda setting dibagi menjadi tiga (3) level, yaitu: Tier 1; Media memberitahukan kepada khalayak tentang apa yang harus dipikirkan, artinya media mengarahkan khalayak untuk berpikir dan menanggapi suatu fenomena yang diinginkan oleh media, tier 2; Media memberi tahu penonton tentang atribut apa yang paling penting dalam sebuah masalah, tingkat 3; Media menyampaikan kepada khalayak, isuisu mana saja yang berkaitan dengan isu yang sedang dipublikasikan. Melalui ketiga tahapan di atas, media berusaha mempengaruhi, mengarahkan dan membentuk persepsi dan perilaku publik terhadap suatu isu atau fenomena yang sedang terjadi (Grififn, 2019)

Severin dan Tankard (2014)dalam bukunya "Communication Theories: Origins, Methods and Uses in the Mass Media", menjelaskan jenis agenda dalam agenda setting beserta dimensi dimensinya, yang terdiri dari; agenda media, agenda publik, dan agenda kebijakan. (Severin, W. J., \& Tankard, Jr, 2014). Pada artikel kali ini penulis memfokuskan pada agenda media, yaitu antara lain; Visibility adalah jumlah dan tingkat keunggulan berita, Audience Salience (tingkat keunggulan audiens), relevansi konten berita dengan kebutuhan audiens dan Valence, yang merupakan cara pemberitaan yang menyenangkan atau tidak menyenangkan.

Steensen (2019) dalam artikelnya yang berjudul "What Does Digital Journalism Studies Look Like?" Memiliki objek kajian yang sama, jurnalisme digital, yang mengedepankan dominasi praktik dan kelembagaan sosial, dibentuk oleh teknologi dan platform baru yang semakin bersimbiosis dengan audiensi (Steensen et al., 2019). Artikel Steensen dan rekan-rekan (2019) ini, hanya menganalisis artikel artikel ilmiah lain yang terkait dengan jurnalisme digital terbitan jurnal Digital Journalism, sedangkan pada penelitian ini penulis menganalisis artikel berita online tentang kegiatan. Mahasiswa Ilmu Komunikasi Fakultas Teknologi Informasi dan Komunikasi Universitas Semarang yang dimuat di Tribunnews.com. Perbedaan lain dengan penelitian kami adalah bahwa analisis dalam penelitian Steenseen menggunakan metode campuran, yaitu kombinasi metode kuantitatif dan kualitatif dalam menganalisis jurnalisme digital, sedangkan dalam artikel kami, kami hanya menggunakan analisis konten kuantitatif untuk melihat konstruksi berita dalam jurnalisme digital. .

(2019) dalam artikel mereka "Digital Journalism: Defined, Refined, or Redefined". Dalam artikel tersebut dijelaskan bahwa yang menjadi titik tolak definisi digitalisasi adalah bagaimana berbagai bidang kehidupan sosial ditata ulang dalam infrastruktur komunikasi dan media digital. Disamping itu, artikel ini membahas tantangan pendefinisian istilah "jurnalisme digital" serta mengemukakan keistimewaan teknologi digital dari sudut pandang pendekatan ilmiah. Artikel Daffy's 
dan Ang ini terdapat kemiripan dengan artikel peneliti terkait jurnalisme digital, terutama dalam hal keunggulan jurnalisme digital. Perbedaan dari kedua artikel ini adalah, artikel Duffy's dan Ang merupakan analisis literatur, sedangkan artikel kami adalah analisis konten kuantitatif dari pemberitaan di media tertentu (Duffy \& Ang, 2019)

Sunarwan (2017), dalam artikelnya yang berjudul "Pencitraan Pemerintah dan Media Lokal" menitik beratkan pada unsur Valence yang muncul pada judul berita objek penelitiannya. Dalam artikel ini, ditunjukan bagaimana valence (valensi) dalam menuliskan judul berita mempengaruhi pencitraan pemerintah daerah di mata masyarakatnya. (Sunarwan, 2017). Sedangkan pada penelitian ini, peneliti tidak hanya melihat dari sisi judul berita tetapi juga dari sisi $5 \mathrm{~W}+1 \mathrm{H}$ serta bagaimana melakukan cover both story dalam penyampaian berita tersebu dalam melihat bagaimana valence yang ada dalam berita berita kegiatan mahasiswa Ilmu Komunikasi Fakultas Teknologi Informasi dan Komunikasi Univeristas Semarang dibentuk sehingga mampu membuat audiens tertarik untuk membaca artikel berita tersebut. Duku (2014) dalam artikelnya "Dampak Media, Penentuan Agenda (Agenda Setting), dan Teori The Spiral of Silence", mengulas mengenai dampak dari agenda setting terhadap audiens yang dikaitkan dengan teori spiral of silence. Artikel ini mengulas bagaimana agenda media membuat audiens menjadi bagian dari minoritas atau mayoritas, apabila menjadi minoritas, maka mereka akan diam (Duku, 2014). Dalam penelitian ini, peneliti sama sama menggunakan agenda setting tetapi lebih menitik beratkan kepada dampaknya dalam jurnalistik online yang saat ini semakin berkembang pesat.
Raditya dan Esfandari ( 2015), mengemukakan bahwa agenda setting memiliki pengaruh yang cukup kuat terhadap agenda publik, yang dibuktikan dengan tingginya pemahaman publik atas suatu informasi yang disampaikan oleh media massa.(Raditya \& Esfandari, 2015). Sedikit berbeda dengan penelitain yang peneliti lakukan, dimana peneliti ingin melihat bagaimana agenda setting memiliki kaitan yang kuat dengan agenda pemilik kepentingan.

Berdasarkan uraian di atas, peneliti ingin mengkaji konstruksi agenda setting dalam berita kegiatan mahasiswa Jurusan Ilmu Komunikasi Fakultas Teknologi Informasi dan Komunikasi Universitas Semarang yang dipublikasikan oleh Tribunnews.com, apakah sesuai dengan harapan stakeholders atau tidak, sehingga muncul hipotesis sebagai berikut;

$\mathrm{H0}$ :Konstruksi berita kegiatan mahasiswa Program studi Ilmu Komunikasi Fakultas Teknologi Informasi dan Komunikasi Universitas Semarang yang dipublikasikan Tribunnews.com tidak sesuai dengan maksud dan tujuan dari Program Studi Ilmu Komunikasi Fakultas Teknologi Informasi dan Komunikasi Universitas Semarang

H1 :Konstruksi berita kegiatan mahasiswa Program studi Ilmu Komunikasi Fakultas Teknologi Informasi dan Komunikasi Universitas Semarang yang dipublikasikan Tribunnews.com sesuai dengan maksud dan tujuan dari Program Studi Ilmu Komunikasi Fakultas Teknologi Informasi dan Komunikasi Universitas Semarang 


\section{METODE}

Barelenson, Holsti, Krippendorff dan Weber dalam Eriyanto (2013), menyatakan bahwa analisis isi kuantitatif merupakan teknik penelitian ilmiah guna mengetahui gambaran karakteristik isi dan menarik inferensi dari isi. Analisis isi digunakan untuk mengidentifikasi secara sistematis isi komunikasi yang tampak (manifest), secara objektif, valid, reliabel, dan dapat direplikasi (Eriyanto, 2013). Analisis isi juga digunakan dalam studi agenda setting. Analisis media yang relevan, menggunakan konten sebagai penentu pentingnya topik berita. Analisi isi juga dapat digunakan untuk meneliti audiens dengan melihat korespondensi antara agenda media dan agenda audiens (Wimmer \& Dominick, 2014)

Analisis isi dalam penelitian ini bersifat deskriptif, yang digunakan untuk menggambarkan karakteristik pesan, dengan menjawab pertanyaan to whom, what, dan how. What digunakan untuk menjawab mengenai apa isi suatu pesan, to whom digunakan untuk menguji hipotesis isi pesan yang ditunjukan pada khalayak yang berbeda, sedangkan how, digunakan untuk menggambarkan isi-isi pesan dalam komunikasi teks, dengan thapan tahapan sebagai berikut; Pertama, penetapan desain atau model penelitian. Di sini ditetapkan berapa media, analisis deskriptif, perbandingan atau korelasi serta banyak atau sedikit objek yang digunakan dan sebagainya. Kedua, pencarian data pokok atau data primer, yaitu teks itu sendiri. Sebagai analisis isi maka teks merupakan objek yang pokok bahkan terpokok. Pencarian dapat dilakukan dengan menggunakan lembar formulir pengamatan tertentu yang sengaja dibuat untuk keperluan pencarian data tersebut Ketiga, pencarian pengetahuan kontekstual agar penelitian yang dilakukan tidak berada di ruang hampa, tetapi terlihat kait-mengait dengan faktor-faktor lain. (Eriyanto, 2013)

Prosedur dasar pembuatan rancangan penelitian dan pelaksanaan studi analisis isi terdiri atas 6 tahapan langkah, yaitu; merumuskan pertanyaan penelitian dan hipotesisnya, melakukan sampling dan menentukan sub sample terhadap sumbersumber data yang telah dipilih. Sub Sampel menurut Wimmer dan Domminick (2014) merupakan 10\%-20\% dari sampel yang digunakan dalam penelitian. Sub sampel digunakan untuk uji reliabilitas yang diujikan kepada coder (Wimmer \& Dominick, 2014). Selanjutnya menyusun kategori yang dipergunakan dalam analisis, dalam penelitian ini, peneliti melakukan kategorisasi sebagai berikut:

Tabel 1. Kategorisasi

\begin{tabular}{|c|c|c|}
\hline $\begin{array}{c}\text { Unit } \\
\text { Analisis }\end{array}$ & Dimensi & Indikator \\
\hline \multirow[t]{7}{*}{$\begin{array}{l}\text { Agenda } \\
\text { Media }\end{array}$} & \multirow[t]{3}{*}{ Visibilitas } & $\begin{array}{l}\text { Kesesuaian } \\
\text { Judul dan Isi }\end{array}$ \\
\hline & & $\begin{array}{l}\text { Ketepatan } \\
\text { Penulisan }\end{array}$ \\
\hline & & $\begin{array}{c}\text { Kesesuaian } \\
\text { Foto } \\
\text { dan Isi }\end{array}$ \\
\hline & \multirow[t]{2}{*}{$\begin{array}{l}\text { Audience } \\
\text { Salience }\end{array}$} & $\begin{array}{c}\text { Opinitative } \\
\text { (berita disusun } \\
\text { secara } \\
\text { objektif) }\end{array}$ \\
\hline & & $\begin{array}{l}\text { Transparansi } \\
\text { Sumber Berita }\end{array}$ \\
\hline & \multirow[t]{2}{*}{ Valensi } & $5 \mathrm{~W}+1 \mathrm{H}$ \\
\hline & & $\begin{array}{l}\text { Cover Both } \\
\text { Story }\end{array}$ \\
\hline
\end{tabular}

Langkah selanjutnya adalah mendata sampel dokumen yang telah dipilih dan melakukan pengkodean, menentukan skala dan item berdasarkan kriteria tertentu untuk 
pengumpulan data, dan terakhir melakukan interpretasi/ penafsiran data yang diperoleh. Urutan langkah langkah ini tidak boleh dilompati atau dibalik. Langkah sebelumnya merupakan prasyarat untuk menentukan langkah berikutnya. Permulaan penelitian itu adalah adanya rumusan masalah atau pertanyaan penelitian yang dinyatakan secara jelas, eksplisit, dan mengarah, serta dapat diukur dan untuk dijawab dengan usaha penelitian (Eriyanto, 2013; Wimmer \& Dominick, 2014)

Selanjutnya peneliti melakukan uji reliabilitas dan validitas. Uji reliabilitas dilakukan dengan pengujian oleh coder atau penguji yang akan membaca dan menilai isi dari sub sampel yang telah ditentukan. Penggunaan multi coder, berfungsi untuk menggeneralisasi dari satu set coders untuk populasi coders potensial serta membangun distribusi koefisien reliabilitas seluruh coders serta memeriksa bentuk dan mencari kemungkinan adanya pengecualian (Neuendrof, 2017). Formula yang digunakan dalam uji reliabilitas ini adalah Cronbach's Alpha, dengan rumus:

m (Mean)

\begin{tabular}{cl}
\hline $1+($ Mean $)(\mathrm{m}-1)$ & \\
Dengan : $\mathrm{m}$ & $=$ Jumlah Coder \\
Mean & $=$ Nilai rata - rata antar \\
juri &
\end{tabular}

Uji reliabilitas dapat diterima apabila hasil nya $\geq 0,70$

Langkah berikutnya adalah melakukan uji validitas menggunakan uji validitas konstruk melihat apakah alat ukur disusun atau diturunkan dari suatu kerangka teori tertentu. Neuendorf (2017) dalam bukunya "The Content Anlysis Guidebook", menyebutkan bahwa alat ukur dianggap memiliki validitas konstruk apapbila diturunkan berdasarkan suatu teori yang telah teruji. (Eriyanto, 2013; Neuendrof, 2017).

Analisis data dalam metode analisis isi ini dilakukan dengan menentukan hipotesis penelitian, dengan dasar pengambilan keputusan : jika probabilitas $>0,05$ maka, $\mathrm{H} 0$ diterima, sementara jika probabilitas $<0,05$ maka, H0 ditolak. Pengujian hipotesis dilakukan menggunakan teknik penghitungan chi square $(\chi 2)$ dengan rumus: $(\mathrm{O}-\mathrm{FE})^{2}$ dimana $\mathrm{O}$ : adalah frekuensi awal

FE FE : adalah frekuensi akhir (nilai baris x kolom / N)

responden $\mathrm{N} \quad$ :adalah jumlah

Penelitian ini dilakukan di Universitas Semarang, mengingat obyek penelitian ini adalah berita terkait kegiatan mahasiswa Ilmu Komunikasi Fakultas Teknologi Informasi dan Komunikasi Universitas Semarang yang dimuat dalam Tribunnews.com 2018 -2019, yang dapat diakses kembali dokumentasinya melalui website berita online tersebut

\section{HASIL DAN PEMBAHASAN}

Lembar koding yang berisi cuplikan berita dan pernyataan penelitian disusun berdasarkan sampling yang telah ditentukan sebagai objek penelitian, selanjutnya peneliti mengambil . Sub Sampel sebanyak 10\%-20\% dari sampel yang digunakan dalam penelitian. Sub sampel tersebut digunakan untuk uji reliabilitas yang diujikan kepada coder yang telah dipilih oleh peneliti berdasarkan reputasi mereka sesuai dengan bidang dalam penelitian ini. Peneliti menggunakan multi coder dalam penelitian ini agar reliabilitas data penelitian ini benar benar dapat diandalkan (Wimmer \& Dominick, 2014).

Populasi sebagai generalisasi atas obyek atau subyek penelitian, harus memiliki kualitas dan karakteristik tertentu yang digunakan peneliti untuk diteliti dan diambil kesimpulannya.(Sugiyono, 2019). Dalam 
penelitian ini, Sampel merupakan 10 Berita tentang Kegiatan Mahasiswa ilmu komunikasi Fakultas Teknologi Informasi dan Komunikasi Universitas Semarang dalam rentang waktu tahun 2018-2019. Berdasarkan data sampling trsebut, peneliti mengambil $20 \%$ atau sebanyak 2 (dua) data untuk dilakukan uji reliabilitas kepada 3 (tiga) orang coder yang telah ditentukan.

Berdasarkan hasil coding dari ketiga coder tersebut, ditemukan nilai antar coder seperti yang tercantum pada tabel 2 , di bawah ini

Tabel 2. Tabel Nilai Antar Coder

\begin{tabular}{|c|l|c|c|c|c|c|}
\hline 2 & $\begin{array}{l}\text { Ketepatan } \\
\text { Penulisan }\end{array}$ & 10 & 8,7 & 1,3 & 1,7 & $\mathbf{0 , 2}$ \\
\hline 3 & $\begin{array}{l}\text { Kesesuaian } \\
\text { Isi dengan } \\
\text { Foto }\end{array}$ & 7 & 8,7 & - & 2,9 & 0,3 \\
\hline 4 & Opinitative & 6 & 8,7 & - & 7,3 & 0,8 \\
\hline 5 & $\begin{array}{l}\text { Transparans } \\
\text { i Sumber } \\
\text { Berita }\end{array}$ & 10 & 8,7 & 1,3 & 1,7 & $\mathbf{0 , 2}$ \\
\hline 6 & 5W+1H & 10 & 8,7 & 1,3 & 1,7 & $\mathbf{0 , 2}$ \\
\hline 7 & $\begin{array}{l}\text { Cover Both } \\
\text { Story }\end{array}$ & 8 & 8,7 & - & 7,3 & 0,8 \\
\hline & $\chi^{\mathbf{2}}$ & \multicolumn{1}{|c|}{2,7} & \\
\hline
\end{tabular}

Berdasarkan Tabel 3, diketahui nilai Chi Square $\left(\chi^{2}\right)$ adalah 2,7, selanjutnya nilai ini akan diperbandingkan dengan nilai $C h i$ Square Table dengan nilai degree of freedom (df) sebesar 6, maka dengan melihat tabel kritis chi square, diketahui nilai kritis chi square pada tingkat signifikansi $1 \%$ adalah 16,812 , pada taraf signifikansi 5\% adalah 12,592 dan pada taraf signifikansi $10 \%$ adalah 10.645 , seperti yang tercantum dalam tabel 4

Tabel 4. Tabel Nilai Kritis Chi Square

\begin{tabular}{|c|c|c|c|}
\hline \multirow{2}{*}{$\begin{array}{c}\text { Derajat } \\
\text { Keabsahan } \\
(d f)\end{array}$} & \multicolumn{3}{|c|}{ Taraf Signifikasi } \\
\cline { 2 - 4 } & $10 \%$ & $5 \%$ & $1 \%$ \\
\hline 1 & 2,706 & 3,841 & 6,635 \\
\hline 2 & 4,605 & 5,991 & 9,210 \\
\hline 3 & 6,251 & 7,851 & 11,341 \\
\hline 4 & 7,779 & 9,488 & 13,277 \\
\hline 5 & 9,236 & 11,070 & 15,080 \\
\hline 6 & 10,645 & 12,592 & 16,812 \\
\hline 7 & 12,017 & 14,067 & 18,475 \\
\hline 8 & 13,362 & 15,507 & 20,090 \\
\hline 9 & 14,684 & 16,919 & 21,666 \\
\hline 10 & 15,987 & 18,307 & 23,309 \\
\hline 11 & 17,725 & 19,675 & 24,725 \\
\hline 12 & 18,549 & 21,026 & 26,217 \\
\hline 13 & 19,812 & 22,362 & 27,688 \\
\hline 14 & 21,064 & 23,685 & 29,141 \\
\hline 15 & 22,307 & 24,996 & 30,578 \\
\hline
\end{tabular}




\begin{tabular}{|l|l|l|l|}
\hline 16 & 23,542 & 26,296 & 32,000 \\
\hline 17 & 24,796 & 27,578 & 33,409 \\
\hline 18 & 25,989 & 28,869 & 34,809 \\
\hline 19 & 27,204 & 30,144 & 36,191 \\
\hline 20 & 28,412 & 31,410 & 37,566 \\
\hline
\end{tabular}

Berdasar nilai chi square yang telah diperoleh peneliti sebesar 2,7, lebih kecil dari nilai kritis chi square pada taraf signifikansi $5 \%$, yaitu 12,592 , sehingga $\mathrm{H} 0$ diterima dan H1 ditolak. Dengan demikian hasil uji hipotesis dalam penelitian ini adalah konstruksi berita kegiatan mahasiswa Program studi Ilmu Komunikasi Fakultas Teknologi Informasi dan Komunikasi Universitas Semarang yang dipublikasikan Tribunnews.com tidak atau belum sesuai dengan maksud dan tujuan dari Program Studi Ilmu Komunikasi Fakultas Teknologi Informasi dan Komunikasi Universitas Semarang.

\section{SIMPULAN}

Hasil penelitian menunjukkan bahwa meskipun agenda media yang disusun dalam pemberitaan sudah sesuai dengan keinginan stakeholders, namun masih belum cukup efektif untuk mempengaruhi khalayak untuk mau mengikuti keinginan stakeholders jika tidak diimbangi dengan frekuensi pemberitaan yang cukup tinggi dalam media massa. Melihat kondisi persaingan antar Universitas dalam menarik calon mahasiswa yang semakin ketat saat ini, alangkah baiknya bagi pemilik kepentingan di Universitas, untuk lebih sering melibatkan mahasiswa dalam kegiatan kegiatan kampus yang dikemas unik, menarik dan interaktif agar menarik media agar lebih sering memberitakan kegiatan kegiatan tersebut sehingga pesan yang ingin disampaikan oleh pemilik kepentingan di Universitas dapat dengan mudah diterima dan dipahami oleh masyarakat.

\section{DAFTAR PUSTAKA}

Anonymous. (2017). Kemahasiswaan. Universitas Semarang. http://usm.ac.id/pages/view/Kemahasis waan

Bradshaw, P. (2017). online journalism handbook (2nd ed.). Routledge.

Duffy, A., \& Ang, P. H. (2019). Digital Journalism: Defined, Refined, or Redefined. Digital Journalism, 7(3), 378385 .

https://doi.org/10.1080/21670811.2019. 1568899

Duku, S. (2014). Dampak Media, Penentuan Agenda (Agenda Setting), dan Teori The Spiral of Silence. Wardah, 15(2), 121131.

Eriyanto. (2013). Analisis Isi Pengantar Metodologi untuk Penelitian Ilmu Komunikasi dan Ilmu - Ilmu Sosial Lainnya. Kencana Prenada Media Group.

Grififn, E. (2019). A FIRSTAT LOOK COMMUNICATION THEORY (10th ed.). McGraw-Hill Education.

McCombs, M. E., Shaw, D. L., \& Weaver, D. H. (2014). New Directions in AgendaSetting Theory and Research. Mass Communication and Society, 17(6), 781802.

https://doi.org/10.1080/15205436.2014. 964871

Neuendrof, K. A. (2017). The Content Analysis Guidebook (2nd ed.). SAGE Publications.

Portnoy, M. (2018, March 2). Rangking 10 
Besar Media Online Indonesia By ComeScore. Teknorush.Com. https://teknorush.com/media-onlineindonesia/

Raditya, R., \& Esfandari, D. A. (2015). Pengaruh Agenda Media Terhadap Agenda Publik Mahasiswa Program Studi Ilmu Komunikasi Telkom University Angkatan 2010 - 2013 (Analisa Agenda Setting Pada Program Mata Najwa Menjelang Pemilu Pilpres 2014). E-Proceeding of Management, 19.

https://openlibrary.telkomuniversity.ac.i $\mathrm{d} /$ home/epublication/id/32.html

Romli, A. S. M. (2015). Jurnalistik Online: Panduan mengelola media online. Nuansa Candekia.

Severin, W. J., \& Tankard, Jr, J. W. (2014). Communication Theories: Origins, Methods and Uses in the Mass Media (5th ed.). Longman.

Siapera, E., \& Veglis, A. (2012). The Handbook of Global Online Journalism. John Wiley \& Sons, Inc.

Steensen, S., Larsen, A. M. G., Hågvar, Y. B., \& Fonn, B. K. (2019). What Does Digital Journalism Studies Look Like? Digital Journalism, 7(3), 320-342. https://doi.org/10.1080/21670811.2019. 1581071

Sugiyono. (2019). Metode penelitian pendidikan:(pendekatan kuantitatif, kualitatif dan $R \& D$ ) (2nd ed.). CV Alpabeta.

Sunarwan, B. (2017). pencitraan Pemerintah dan Media Lokal. Jurnal Studi Komunikasi Dan Media, 21(1), 25-41. https://doi.org/10.31445/jskm.2017.210 103

Tjiptono, F. (2015). Strategi Pemasaran. Penerbit ANDI.

Wimmer, R. D., \& Dominick, J. R. (2014). MASS MEDIA RESEARCH (10th ed.). Cengage Learning. 